\title{
Application of Furan-Based Dicarboxylic Acids in Bio-Derived Dimethacrylate Resins
}

\author{
Tuomo P. Kainulainen, Pyry Erkkilä, Terttu I. Hukka, Juho A. Sirviö, and Juha P. Heiskanen*
}

Cite This: ACS Appl. Polym. Mater. 2020, 2, 3215-3225

Read Online

Traditional dimethacrylate from bisphenol A (BisGMA):
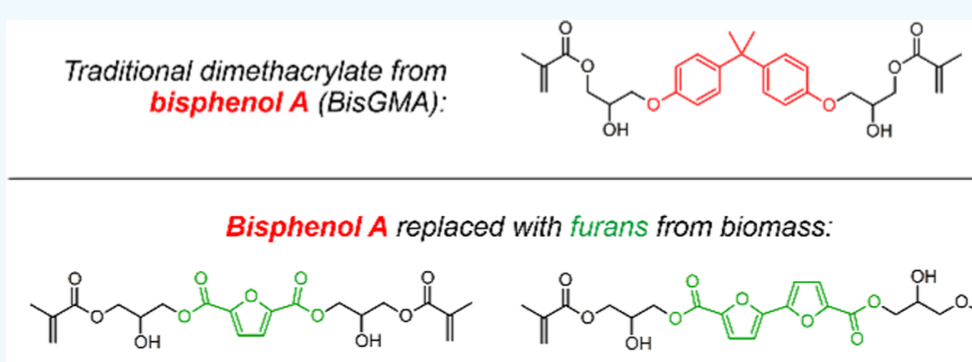

Furan dimethacrylate from FDCA<smiles>C=C(C)C(=O)OCC(O)COC(=O)c1ccc(-c2ccc(C(=O)OCC(O)COC(=O)C(C)C)o2)o1</smiles>

Bifuran dimethacrylate from BFDCA

ABSTRACT: Two renewable dicarboxylic acids, furan-2,5-dicarboxylic acid and 2,2'-bifuran-5,5'-dicarboxylic acid, were applied as bisphenol A substitutes to prepare partially bio-based dimethacrylate resins. The furan-based dimethacrylates were synthesized using their diglycidyl esters as intermediates, which were then reacted with methacrylic acid. This reaction was found to give isomeric mixtures, where the formed methacrylate end group had three different configurations as elucidated using one-dimensional (1D) and two-dimensional (2D) NMR. The ratio between the different end groups could be controlled to an extent by using 1,1,1,3,3,3hexafluoroisopropanol as the sole reagent to facilitate a reaction between the furan diglycidyl esters and methacrylic acid. The control over the configuration of the methacrylate end group is demonstrated to be a possible tool to influence the properties of the resultant dimethacrylate monomer and the cured resin. The bifuran dimethacrylates were found to have viscosities of ca. 110-120 $\mathrm{Pa} \cdot \mathrm{s}$ at $25{ }^{\circ} \mathrm{C}$, while the furan dimethacrylate had a viscosity of about $40 \mathrm{~Pa} \cdot \mathrm{s}$ at $25^{\circ} \mathrm{C}$. It is demonstrated that by diluting the furanbased dimethacrylates with $40 \mathrm{wt} \%$ of methacrylated eugenol, a bio-based reactive diluent, the liquid resins could be cured into thermosets with glass-transition temperatures of $177-209^{\circ} \mathrm{C}$ and $5 \%$ mass loss temperatures of $359-375{ }^{\circ} \mathrm{C}$ under a nitrogen atmosphere.

KEYWORDS: renewable, furan, furfural, HMF, methacrylate, thermoset

\section{INTRODUCTION}

Biomass-based thermosets derived from furans have long been used in various applications, including composite materials and binders in molds for metal casting, to name a couple. ${ }^{1}$ A classic example of a furan thermoset is the dark, insoluble material that can be formed by treating furfuryl alcohol (FA) with acid catalysts. ${ }^{2}$ Due to the useful characteristics of FA resins, they have historically been the chief use of furfural, which is the precursor. Furfural has long had a position as a simple, cheap biochemical, though besides reduction to FA, its uses were otherwise limited to several smaller niche applications. ${ }^{3}$ 5(Hydroxymethyl)furfural (HMF) is another important bridge between biomass and a plethora of possible furan-derived chemicals and biopolymers. Currently, both furfural and HMF attract considerable interest, as both compounds can be obtained directly from sugars via dehydration. ${ }^{4-8}$ However, challenges remain in not only developing efficient and economically attractive routes to furfural and HMF starting from biomass but also coming up with new ways of utilizing these furans in polymers so that they can replace current oilbased polymers.

Furans potentially fulfilling the demand for renewable materials are frequently reported in the literature: poly(ethylene furanoate) (PEF) demonstrates that HMF-based furan-2,5-dicarboxylic acid (FDCA) can confer polymers with excellent physical properties, which is one reason why FDCA is an intensely studied monomer, as outlined in recent reviews on the matter., 90 Thanks to its structural furan rings, the gas permeability of PEF is dramatically reduced compared to that of traditional nonrenewable polymers in its class, such as poly(ethylene terephthalate). On the other hand, it is the rich

Received: April 7, 2020

Accepted: June 30, 2020

Published: June 30, 2020 
Scheme 1. Proposed Furan-Based Alternatives for Diglycidyl and Dimethacrylate Resins Derived from Bisphenol A

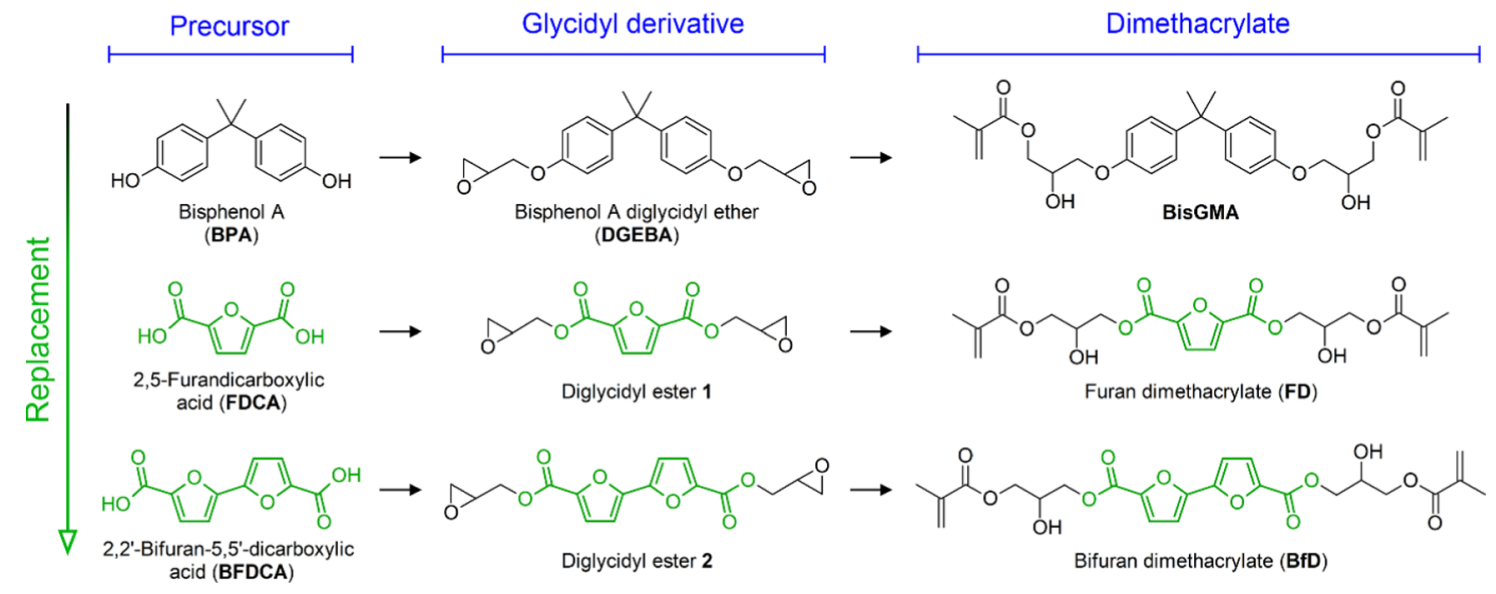

chemistry of furans that is exploited with strategies like utilizing Diels-Alder reactions to assemble polymer networks that cross-link in a thermally reversible manner. ${ }^{11,12}$

Despite furans traditionally having a strong association with thermosets, fewer reports of furan analogues for current, widely used oil-based thermosets seem to exist. ${ }^{13}$ Since the diglycidyl ether of bisphenol A (DGEBA) is an important monomer found in epoxy resins, it has been one key target for replacement with furan alternatives: the condensation product of acetone and furfuryl alcohol is perhaps one of the closest structural furan analogues to DGEBA. ${ }^{14}$ More recently, the diglycidyl ester of FDCA ${ }^{15,16}$ (1, Scheme 1$)$ was proposed as a DGEBA alternative. To this end, Meng et al. have reported the application of both diglycidyl ester $\mathbf{1}^{16}$ and its ether analogue ${ }^{17}$ in amine-hardened epoxy systems. The ether analogue substitutes the carbonyl moieties for methylene bridges, and the subtle variation in structure resulted in notable differences: the 2,5-methylene substitution pattern of the furan ether led to much lower glass-transition temperatures $\left(T_{\mathrm{g}}\right)$ relative to the DGEBA control, though excellent mechanical properties were observed at lower temperatures. In an investigation by $\mathrm{Hu}$ et al., ${ }^{18}$ the same furan diglycidyl ether was more comparable in characteristics to 1,4-benzenedimethanol-derived glycidyl ethers, which are also structurally more related. In contrast, diglycidyl ester 1 provided both good mechanical properties and a higher $T_{\mathrm{g}}$ to the cured resin, though the monomer is a solid unlike the ether, which is a low-viscosity liquid. ${ }^{16}$ This comparison would suggest that the coplanar carbonyl groups of the FDCA-derived monomer may be an important feature that influences several properties. The lack of hydrogen atoms next to the furan ring also seems to result in better thermal stability as could be surmised from thermogravimetric analyses (TGA), where the ester-derived resins showed higher temperatures for the $5 \%$ mass loss relative to the diglycidyl ether resins. ${ }^{17}$ The $\alpha$-position hydrogens have previously been shown to be reactive under some conditions and could potentially lead to changes in properties over time. ${ }^{19,20}$ Diesters of furan carboxylic acids could therefore be considered a base from which to develop furan-based resins for applications that require good thermal properties.

As depicted in Scheme 1, the current study expands from diglycidyl compounds to a related class of cross-linkable dimethacrylate monomers. A notable compound in this class is the dimethacrylate derivative of bisphenol A known often as BisGMA, which is perhaps best known for its use in dental applications. $^{21,22}$ BisGMA and other similar dimethacrylates are usually viscous liquids and cross-link via radical polymerization of the methacrylic double bonds. The resins are also often modified with reactive diluents, such as styrene or triethylene glycol dimethacrylate (TEGDMA), which can improve workability and cured properties. While some simple furan methacrylates have been characterized before, ${ }^{23,24}$ BisGMA-like dimethacrylates FD and BfD (Scheme 1), which are based on furan dicarboxylic acids, have not been previously described. Only the structure of FD appears in a patent. $^{25}$

In this paper, two biomass-derived, furan-based dicarboxylic acids are used as the basis for dimethacrylates, which bear structural similarities to BisGMA. Of the furan dimethacrylates, FD represents an HMF-derived structure, while $\mathrm{BfD}$ represents an upgraded furfural derivative with two furan rings. Previously, Mori et al. and our group have demonstrated that the melting and glass-transition temperatures are increased in linear polyesters when FDCA is substituted with 2,2'bifuran-5,5'-dicarboxylic acid (BFDCA)..$^{26,27}$ We envisioned that the relatively high planarity and stiffness of the furan cores might realize dimethacrylate resins with thermomechanical properties comparable with BisGMA. The properties of the cured resins are also explored via compositions containing methacrylated eugenol (ME) as a bio-based reactive diluent (Scheme 2). Being a derivative of eugenol, ME is a promising

Scheme 2. Strategy for Testing the Novel Dimethacrylates with a Renewable Reactive Diluent, and the Percentage of Carbon from Biomass Assuming Furfural, HMF, and Eugenol Contain $100 \%$ Carbon from Biomass

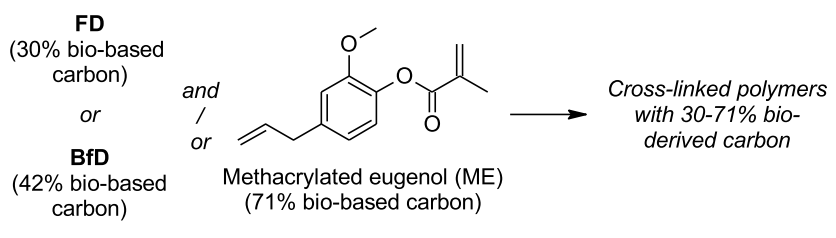

candidate to substitute certain petrochemicals in thermosetting resins that appear in various applications. ${ }^{28-31}$ Due to its methacrylic and allylic double bonds, ME can either be crosslinked alone or mixed with other unsaturated compounds to form stiff and thermally resilient materials. The results here show that dimethacrylates prepared from furan diacids could in 


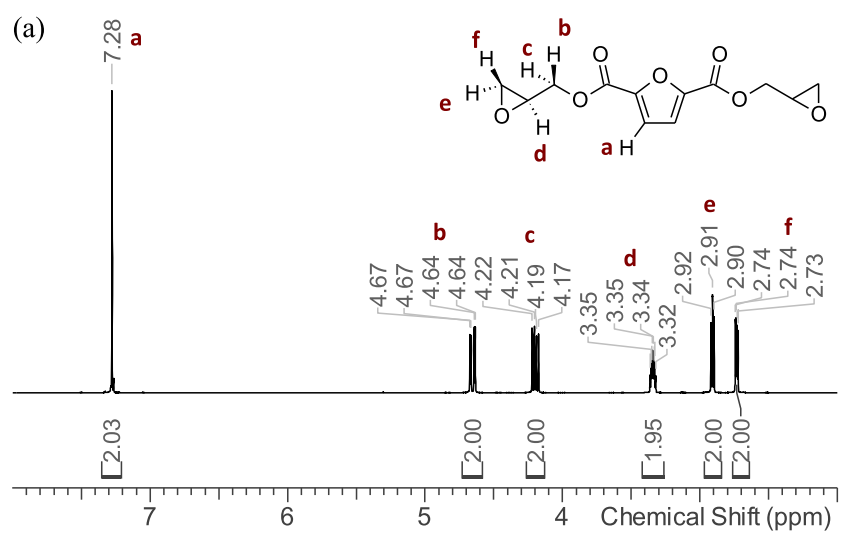

(b)

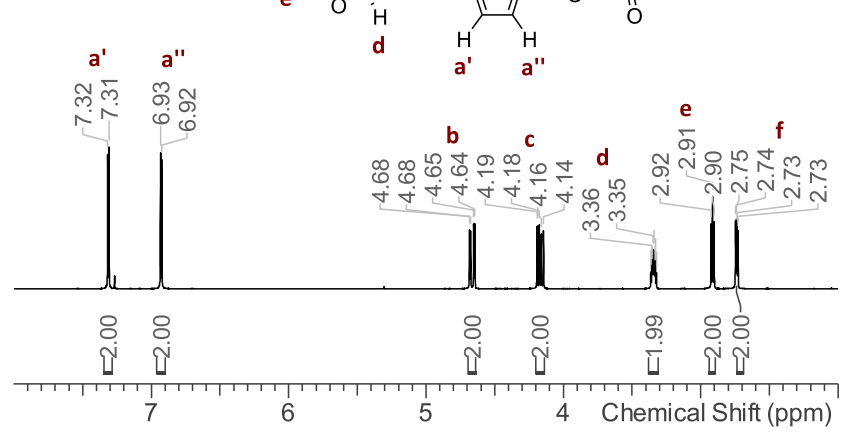

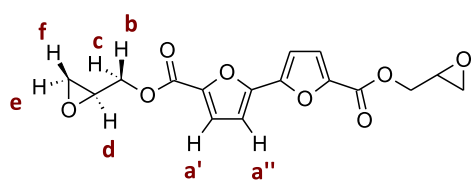

Figure 1. ${ }^{1} \mathrm{H}$ NMR spectra of furan diglycidyl ester 1 (a) and bifuran diglycidyl ester 2 (b) in $\mathrm{CDCl}_{3}$.

(a)

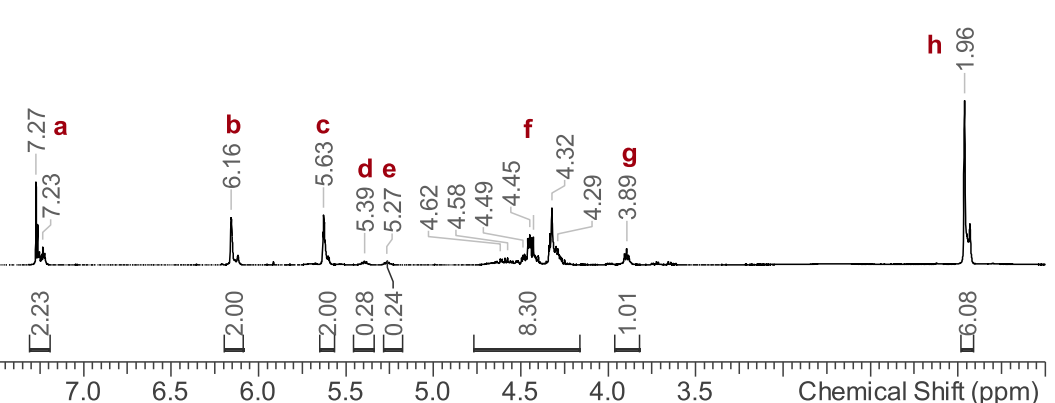

(b)

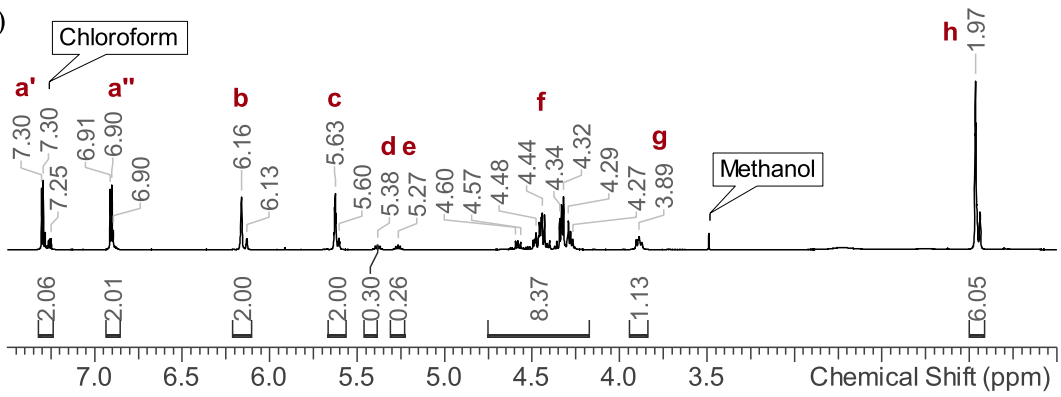<smiles>Cc1cc(C)c(C)o1</smiles>

\section{End group ratio \\ A:B:C $=74: 12: 14$}

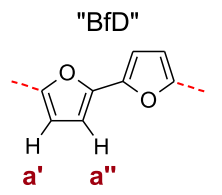

End group ratio A:B:C $=72: 13: 15$

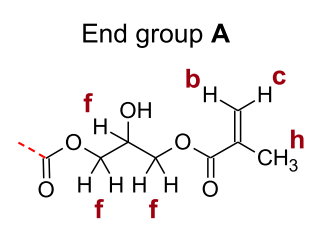

End group $\mathbf{B}$

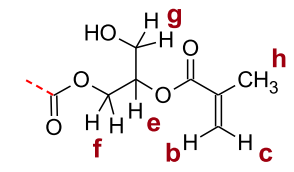

End group $\mathbf{C}$

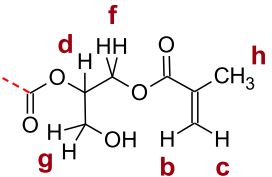

Figure 2. ${ }^{1} \mathrm{H}$ NMR end group assignment for $\mathrm{FD}(\mathrm{a})$ and $\mathrm{BfD}(\mathrm{b})$ in $\mathrm{CDCl}_{3}$.

fact be useful for obtaining properties that are competitive with those of BisGMA resins.

\section{EXPERIMENTAL SECTION}

Commercial solvents and reagents were used as received, unless otherwise specified. Methacrylic acid $(>99.5 \%)$ stabilized with monomethyl ether hydroquinone was used in the reactions. The reactions were conducted under an atmosphere of argon unless otherwise noted. Triethylamine was dried over $4 \AA$ molecular sieves and distilled prior to use. Glycidol was distilled under reduced pressure (3 mbar) and subsequently stored as a mixture with dichloromethane $(1: 1 \mathrm{v} / \mathrm{v})$ at $-20{ }^{\circ} \mathrm{C}$ prior to use. All NMR spectra were acquired at $25^{\circ} \mathrm{C}$ using a $400 \mathrm{MHz} \mathrm{NMR}$ instrument (Bruker), with chemical shifts referenced to TMS at $0.00 \mathrm{ppm}$.

Furan Diglycidyl Ester (1). To a stirred mixture of FDCA (1.56 g) and dimethylformamide (3 drops) in $20 \mathrm{~mL}$ of dry dichloromethane, $\mathrm{SOCl}_{2}$ (2.5 equiv) was added under an argon flow. The solution was then warmed to reflux and allowed to be stirred for $10 \mathrm{~h}$, which yielded a colorless solution. After evaporation of the solvent, off-white crystals were afforded. The crude diacyl chloride was dissolved in dry dichloromethane $(40 \mathrm{~mL})$ at $0{ }^{\circ} \mathrm{C}$ and triethylamine (2.25 equiv) was slowly added, yielding a yellow solution to which glycidol ( 2.25 equiv) was introduced over 15 min using a syringe. The mixture was then allowed to warm to $20^{\circ} \mathrm{C}$ while stirring. After $1 \mathrm{~h}$, the mixture was washed successively with deionized water and saturated aqueous $\mathrm{NaHCO}_{3}$. After drying with anhydrous $\mathrm{Na}_{2} \mathrm{SO}_{4}$, the organic solution was filtered through a thin layer of silica gel. Evaporation of the solvent yielded a viscous, yellow oil that very rapidly crystallized at room temperature. Impurities were removed by dissolving the crude product in a minimum amount of warm dichloromethane $(5 \mathrm{~mL})$, from which the product was precipitated with the addition of diisopropyl ether $(40 \mathrm{~mL})$. The white precipitate was filtered and washed with several small portions of diisopropyl ether and finally with small portions of methanol. After drying in vacuum, furan diglycidyl ester $\mathbf{1}$ was isolated as a white powder $(2.38$ g, 89\%), which ${ }^{1} \mathrm{H}$ NMR analysis confirmed as the desired product (Figure 1a). $T_{\mathrm{m}}: 89^{\circ} \mathrm{C}$ (DSC). ${ }^{1} \mathrm{H}$ NMR (400 MHz, $\left.\mathrm{CDCl}_{3}, \mathrm{ppm}\right): \delta$ $7.28(\mathrm{~s}, 2 \mathrm{H}), 4.66(\mathrm{dd}, 2 \mathrm{H}, J=12.2,3.2 \mathrm{~Hz}), 4.20(\mathrm{dd}, 2 \mathrm{H}, J=12.2$, $6.4 \mathrm{~Hz}), 3.35(\mathrm{~m}, 2 \mathrm{H}), 2.91(\mathrm{~m}, 2 \mathrm{H}), 2.74(\mathrm{dd}, 2 \mathrm{H}, J=4.9,2.5 \mathrm{~Hz})$. ${ }^{13} \mathrm{C}$ NMR (100 MHz, $\left.\mathrm{CDCl}_{3}, \mathrm{ppm}\right): \delta 157.5,146.5,119.0,66.0,49.1$, 44.8.

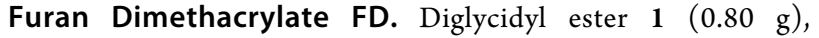
methacrylic acid (3 equiv), and triethylamine (1 equiv) were added to dichloromethane $(1.5 \mathrm{~mL})$ in a $5 \mathrm{~mL}$ reaction tube. The mixture was agitated at $70{ }^{\circ} \mathrm{C}$ overnight $(20 \mathrm{~h})$ under air in the sealed tube. The mixture was then diluted with ethyl acetate and washed successively with small portions of saturated aqueous $\mathrm{NaHCO}_{3}$, deionized water, and brine. After drying with anhydrous $\mathrm{Na}_{2} \mathrm{SO}_{4}$, filtration of the ethyl acetate solution through silica gel followed by evaporation yielded a viscous, light yellow liquid. Residual ethyl acetate was removed by adding methanol $(5 \mathrm{~mL})$ and evaporating 


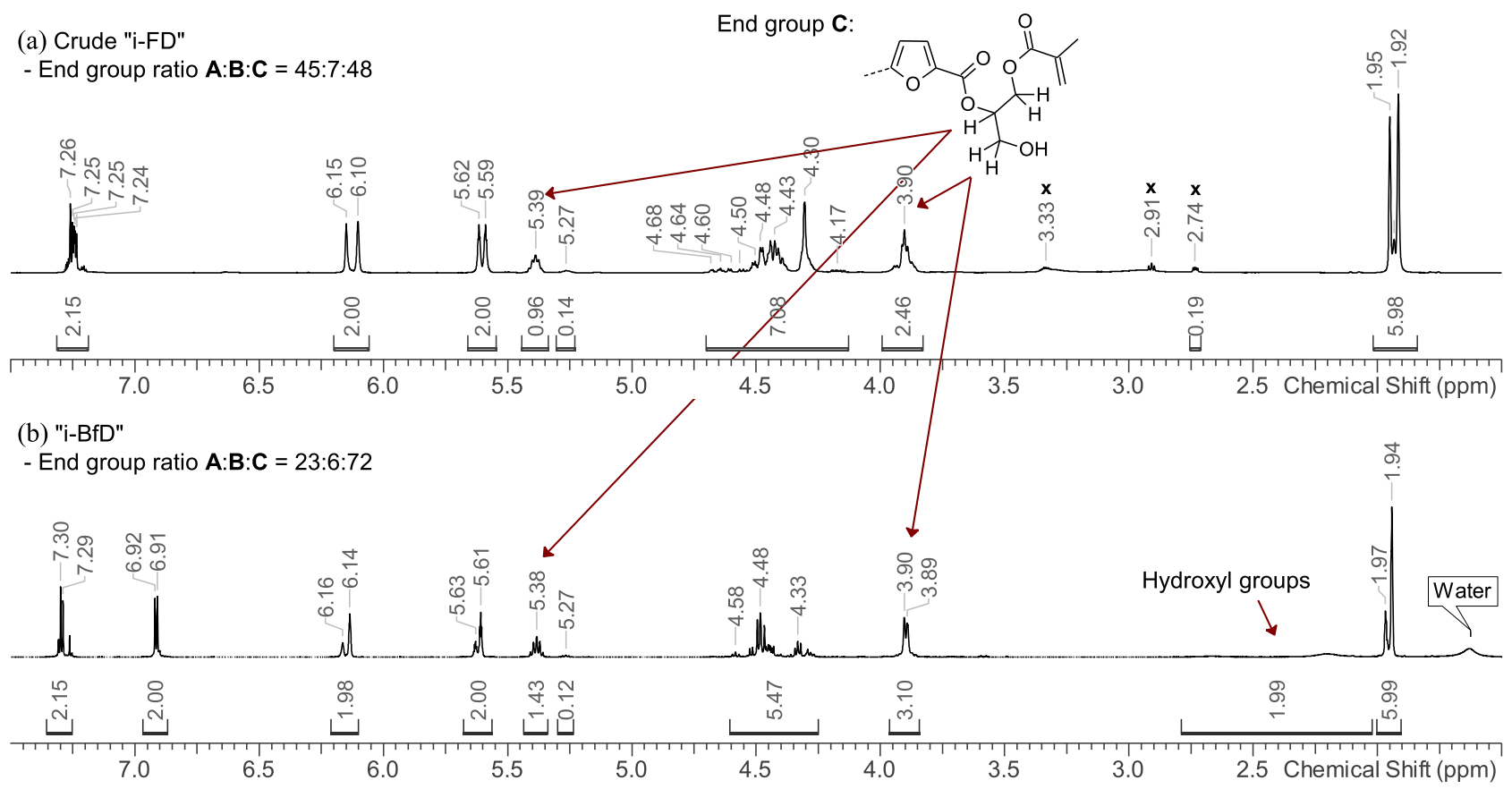

Figure 3. Product obtained in the HFIP-MAA system from diglycidyl ester 1 (a) and diglycidyl ester 2 (b). Signals from residual glycidyl ester end groups are denoted by $x$. Solvent: $\mathrm{CDCl}_{3}$. Refer to Figure 2 for end group structures $\mathbf{A}$ and $\mathbf{B}$.

under reduced pressure at $50{ }^{\circ} \mathrm{C}$ and then repeating the procedure once, giving a viscous pale yellow liquid (1.13 g, 86\%), which NMR analysis showed was the desired dimethacrylate (Figures 2, S13, S16, and S17).

Furan Dimethacrylate i-FD. Diglycidyl ester $1(134.1 \mathrm{mg})$ and methacrylic acid (3 equiv) were dissolved in 1,1,1,3,3,3-hexafluoroisopropanol (HFIP) $(0.5 \mathrm{~mL})$. The mixture was agitated at $65^{\circ} \mathrm{C}$ for $50 \mathrm{~h}$ under air in a sealed tube. The purification procedure used for FD yielded a colorless, highly viscous liquid as the crude product (210.6 mg, 95\%). The methacrylate/epoxy ratio in the crude product was determined to be ca. 91:9 by ${ }^{1} \mathrm{H}$ NMR integral analysis (Figure 3). Unknown insoluble (acetone, chloroform) impurities were observed in the product and the NMR sample, appearing as white particles.

2,2'-Bifuran-5,5'-dicarboxylic Acid. Dimethyl 2,2'-bifuran-5,5' dicarboxylate $(3.00 \mathrm{~g})$, prepared following our previous method, ${ }^{32}$ was hydrolyzed at reflux using 10 -fold excess of aqueous $\mathrm{NaOH}(10 \%$ solution). Once the mixture turned clear, the dicarboxylic acid was precipitated by adding concentrated hydrochloric acid to the reaction mixture at $0{ }^{\circ} \mathrm{C}$ until the $\mathrm{pH}$ was $1-2$. The dicarboxylic acid was separated by filtering the acidified slurry, which gave a dense cake. The cake was successively rinsed with deionized water and methanol and allowed to dry in air. Further drying was accomplished under vacuum at $60{ }^{\circ} \mathrm{C}$. To ensure dryness, the dry cake was crushed and ground into a fine powder and then dried to constant weight under vacuum. 2,2'-Bifuran-5,5'-dicarboxylic acid was collected as a fine, offwhite powder $(2.30 \mathrm{~g}, 87 \%) .{ }^{1} \mathrm{H} \mathrm{NMR}\left(400 \mathrm{MHz},\left(\mathrm{CD}_{3}\right)_{2} \mathrm{SO}, \mathrm{ppm}\right)$ : $\delta 13.38(\mathrm{br} \mathrm{s}, 2 \mathrm{H}), 7.35(\mathrm{~d}, 2 \mathrm{H}, J=3.4 \mathrm{~Hz}), 7.08(\mathrm{~d}, 2 \mathrm{H}, J=3.4 \mathrm{~Hz})$. ${ }^{13} \mathrm{C}$ NMR $\left(100 \mathrm{MHz},\left(\mathrm{CD}_{3}\right)_{2} \mathrm{SO}, \mathrm{ppm}\right): \delta 158.8,146.9,144.9,119.3$, 109.8 .

Bifuran Diallyl Ester (BfDA). 2,2'-Bifuran-5,5'-dicarboxylic acid $(0.22 \mathrm{~g})$ was reacted with allyl bromide (4 equiv) and $\mathrm{Na}_{2} \mathrm{CO}_{3}(2.25$ equiv) in dry dimethylformamide $(2.5 \mathrm{~mL})$. After $24 \mathrm{~h}$ at $70{ }^{\circ} \mathrm{C}$, the reaction was stopped, and the mixture was diluted with ethyl acetate and washed successively with small portions of deionized water and brine. After evaporation under reduced pressure, the product was obtained as an off-white, crystalline powder $(0.26 \mathrm{~g}, 85 \%) .{ }^{1} \mathrm{H}$ NMR $\left(400 \mathrm{MHz}, \mathrm{CDCl}_{3}, \mathrm{ppm}\right): \delta 7.28(\mathrm{~d}, 2 \mathrm{H}, J=3.7 \mathrm{~Hz}), 6.91(\mathrm{~d}, 2 \mathrm{H}, J=$ $3.7 \mathrm{~Hz}), 6.03(\mathrm{ddt}, 2 \mathrm{H}, J=17.2,10.4,5.8 \mathrm{~Hz}), 5.43(\mathrm{dq}, 2 \mathrm{H}, J=17.2$, $1.5 \mathrm{~Hz}), 5.32(\mathrm{dq}, 2 \mathrm{H}, J=10.4,1.2 \mathrm{~Hz}), 4.83(\mathrm{dt}, 2 \mathrm{H}, J=5.8,1.5$
$\mathrm{Hz}) .{ }^{13} \mathrm{C}$ NMR $\left(100 \mathrm{MHz}, \mathrm{CDCl}_{3}, \mathrm{ppm}\right): \delta$ 158.0, 148.3, 144.3, 131.7, 119.7, 118.9, 109.4, 65.6 .

Bifuran Diglycidyl Ester (2); Oxidation of BfDA. Previously reported procedures ${ }^{15,16}$ for the oxidation of FDCA diallyl ester were adapted. Briefly, bifuran diallyl ester $(0.5 \mathrm{mmol})$ was combined with meta-chloroperoxybenzoic acid (77\% purity, 5 equiv) in dichloromethane $(5 \mathrm{~mL})$ and agitated for 2 days at $40{ }^{\circ} \mathrm{C}$ in a sealed reaction tube. After dilution with dichloromethane, the reaction mixture was washed successively with aqueous $\mathrm{Na}_{2} \mathrm{SO}_{3}$ and $\mathrm{NaHCO}_{3}$ solutions. The organic solution was dried with anhydrous $\mathrm{Na}_{2} \mathrm{SO}_{4}$ and evaporated to dryness to yield a crude product $(113.8 \mathrm{mg},<68 \%)$, which was analyzed using ${ }^{1} \mathrm{H}$ NMR (Figure S5).

Bifuran Diglycidyl Ester (2). 2,2'-Bifuran-5,5'-dicarboxylic acid $(2.22 \mathrm{~g})$ was reacted with $\mathrm{SOCl}_{2}$ (2.5 equiv) and 3 drops of dimethylformamide in dry dichloromethane $(20 \mathrm{~mL})$. After $10-12 \mathrm{~h}$ at reflux, a yellow solution with a large portion of crystalline precipitate was obtained. The solution was evaporated to dryness to yield crude bifuran diacyl chloride (Figure S6). The crude diacyl chloride mixed with dry dichloromethane $(40 \mathrm{~mL})$ was cooled to 0 ${ }^{\circ} \mathrm{C}$, and triethylamine ( 2.25 equiv) was added to the mixture under argon. Then, glycidol (2.25 equiv) in dichloromethane $(1: 1 \mathrm{v} / \mathrm{v})$ was added to the solution over $15 \mathrm{~min}$ using a syringe. Strong agitation was maintained during and after the addition. The mixture was allowed to warm to $20^{\circ} \mathrm{C}$, and the reaction was continued for $1 \mathrm{~h}$. The resulting mixture was diluted with dichloromethane $(100 \mathrm{~mL})$ and the crude product was separated as with diglycidyl ester $\mathbf{1}$. Further purification was accomplished by triturating the crude product in warm ethyl acetate-hexane mixture $(50 \mathrm{~mL}, 1: 4 \mathrm{v} / \mathrm{v})$, from which the solid product was filtered off after stirring. The product was carefully rinsed with several small portions of methanol and dried in air to yield bifuran diglycidyl ester $\mathbf{2}$ as a white powder (2.88 g, 86\%), which was confirmed to be the diglycidyl ester via ${ }^{1} \mathrm{H}$ NMR analysis (Figure $1 \mathrm{~b}) . T_{\mathrm{m}}: 165^{\circ} \mathrm{C}$ (DSC). ${ }^{1} \mathrm{H}$ NMR $(400 \mathrm{MHz}$, $\left.\mathrm{CDCl}_{3}, \mathrm{ppm}\right): \delta 7.31(\mathrm{~d}, 2 \mathrm{H}, J=3.7 \mathrm{~Hz}), 6.93(\mathrm{~d}, 2 \mathrm{H}, J=3.7 \mathrm{~Hz})$, $4.67(\mathrm{dd}, 2 \mathrm{H}, J=12.2,3.2 \mathrm{~Hz}), 4.17(\mathrm{dd}, 2 \mathrm{H}, J=12.2,6.4 \mathrm{~Hz}), 3.35$ $(\mathrm{m}, 2 \mathrm{H}), 2.92(\mathrm{dd}, 2 \mathrm{H}, J=4.9,4.2 \mathrm{~Hz}), 2.74(\mathrm{dd}, 2 \mathrm{H}, J=4.9,2.5$ $\mathrm{Hz}) \cdot{ }^{13} \mathrm{C}$ NMR $\left(100 \mathrm{MHz}, \mathrm{CDCl}_{3}, \mathrm{ppm}\right): \delta 157.9,148.4,143.9$, $120.2,109.6,65.6,49.2,44.7$.

Bifuran Dimethacrylate BfD. Using diglycidyl ester $2(0.67 \mathrm{~g})$, the procedure used to prepare $\mathrm{FD}$ was followed to yield $\mathrm{BfD}$ as a viscous, pale yellow liquid $(0.85 \mathrm{~g}, 83 \%)$. Upon standing at room 
temperature for several days, small crystalline precipitates were observed in the product.

Bifuran Dimethacrylate i-BfD. The reaction was conducted in the same way as with i-FD but using diglycidyl ester $2(0.84 \mathrm{~g})$ in 2.5 $\mathrm{mL}$ of HFIP. Purification gave $\mathrm{i}-\mathrm{BfD}$ as a colorless, highly viscous liquid (1.23 g, 97\%).

Methacrylated Eugenol. Methacrylated eugenol was prepared with slight modifications on various methods found in the literature. $^{33,34}$ First, methacrylic acid $(4.30 \mathrm{~mL})$ was slowly added to $\mathrm{SOCl}_{2}$ (1.05 equiv) at $0{ }^{\circ} \mathrm{C}$. Two drops of dimethylformamide were added as a catalyst. The mixture was then slowly heated to $50^{\circ} \mathrm{C}$ in a closed $20 \mathrm{~mL}$ reaction tube. Once the evolution of gas stopped, after 2-3 h, the crude methacryloyl chloride was drawn into a syringe and added dropwise into a mix of eugenol ( 0.9 equiv) and triethylamine ( 0.9 equiv) in dry ethyl acetate at $0{ }^{\circ} \mathrm{C}$. The mixture was then heated to $40^{\circ} \mathrm{C}$ for $1 \mathrm{~h}$ and subsequently filtered and diluted with ethyl acetate. After washing with saturated aqueous $\mathrm{NaHCO}_{3}$, deionized water, and brine, the organic layer was dried with anhydrous $\mathrm{Na}_{2} \mathrm{SO}_{4}$ and filtered. Ethyl acetate was removed via rotary evaporation under reduced pressure to yield a light yellow oil as the crude product (10.353 g, 99\%). Purification of the crude mixture via flash chromatography ${ }^{35}$ (silica gel, ethyl acetate:hexane 1:9 v/v) yielded methacrylated eugenol as a colorless oil ( $8.03 \mathrm{~g}, 77 \%)$. For storage, monomethyl ether hydroquinone was added $(200 \mathrm{ppm})$ as a stabilizer. ${ }^{1} \mathrm{H}$ NMR (400 MHz, $\left.\mathrm{CDCl}_{3}, \mathrm{ppm}\right): \delta 6.98(\mathrm{~d}, 1 \mathrm{H}, J=7.8$ $\mathrm{Hz}), 6.81(\mathrm{~d}, 1 \mathrm{H}, J=2.0 \mathrm{~Hz}), 6.79(\mathrm{dd}, 1 \mathrm{H}, J=7.8,2.0 \mathrm{~Hz}), 6.42-$ $6.31(\mathrm{~m}, 1 \mathrm{H}), 5.98(\mathrm{ddt}, 1 \mathrm{H}, J=16.9,10.1,6.8 \mathrm{~Hz}), 5.78-5.71(\mathrm{~m}$, $1 \mathrm{H}), 5.18-5.05(\mathrm{~m}, 2 \mathrm{H}), 3.82(\mathrm{~s}, 3 \mathrm{H}), 3.4(\mathrm{~d}, 2 \mathrm{H}, J=6.8 \mathrm{~Hz}), 2.13-$ $2.03(\mathrm{~m}, 3 \mathrm{H})$.

Resin Preparation and Hardening. For each mixed resin composition, the components were homogenized together in a small amount of dichloromethane, which was subsequently removed via vacuum evaporation. The mixed resins were prepared so that they contained furan-based component and methacrylated eugenol in a $60: 40$ ratio by mass, as designated by subscripts, e.g., $\mathrm{FD}_{60} \mathrm{ME}_{40}$. tertButyl peroxybenzoate ( $2 \mathrm{wt} \%)$ was added as the radical initiator in all cases (not added for viscosity measurements). The resins were transferred into a stainless steel mold coated with PTFE (preheated to $90{ }^{\circ} \mathrm{C}$ in the case of undiluted dimethacrylates), and the resin in the mold was then degassed under reduced pressure $(5 \mathrm{mbar})$ after the transfer. The mold was placed under argon and heated in an oven at $90{ }^{\circ} \mathrm{C}$ for $1 \mathrm{~h}, 150{ }^{\circ} \mathrm{C}$ for $5 \mathrm{~h}$, and finally for postcure $2 \mathrm{~h}$ at $180^{\circ} \mathrm{C}$, following the cure method in ref 36 . The specimens were carefully ejected from the molds after cooling and then used for dynamic mechanical analysis (DMA). The cured specimens subjected to Soxhlet extraction (jacketed extractor, cellulose cup, dichloromethane as solvent) were stored inside a desiccator to remove moisture and stabilize the sample weights. The dichloromethane extracts were concentrated under reduced pressure and analyzed using ${ }^{1} \mathrm{H}$ NMR (Figure S24). The extracted resin pieces were dried under reduced pressure at $120-140{ }^{\circ} \mathrm{C}$ and weighed, with the mass loss taken as the soluble content.

Dynamic Viscosity. Measurements were done on a Discovery HR-1 rheometer (TA Instruments), with parallel plate geometry (40 $\mathrm{mm}$ diameter) at temperatures of $25,30,40$, and $50{ }^{\circ} \mathrm{C}$, where applicable, with shear rates between 1 and $100 \mathrm{~s}^{-1}$.

Differential Scanning Calorimetry (DSC). Neat and mixed methacrylates with added 2 wt $\%$ of tert-butyl peroxybenzoate were scanned from 25 to $250{ }^{\circ} \mathrm{C}$ at $10{ }^{\circ} \mathrm{C} / \mathrm{min}$ using a DSC821e instrument (Mettler-Toledo). Forty microliter $\mathrm{Al}$ pans with a pierced lid under a $50 \mathrm{~cm}^{3} / \mathrm{min} \mathrm{N}_{2}$ flow were used. Three-four milligrams of resin was accurately weighed into the pan, and the weight of the closed pan + sample was measured before and after the experiments to observe possible volatilization of resin components.

Thermogravimetric Analysis (TGA). The decomposition properties and thermal stability of the samples, ca. $13 \mathrm{mg}$, were studied with a TGA851e thermogravimetric analyzer (MettlerToledo). Each sample was placed into a $70 \mu \mathrm{L} \mathrm{Al}_{2} \mathrm{O}_{3}$ crucible, which was covered by a lid with a hole in the middle and heated from
50 to $1000{ }^{\circ} \mathrm{C}$ under a nitrogen flow $\left(95 \mathrm{~cm}^{3} / \mathrm{min}\right)$ using a heating rate of $20{ }^{\circ} \mathrm{C} / \mathrm{min}$.

Dynamic Mechanical Analysis (DMA). DMA Q800 (TA Instruments) in tensile mode (10-15 $\mathrm{mm}$ sample length, $0.1 \%$ strain, $1 \mathrm{~Hz}$ frequency, and $125 \%$ force track) was used to evaluate the thermomechanical properties from rectangular specimens ca. $1 \mathrm{~mm}$ thick ( $3 \mathrm{~mm}$ width). The temperature was ramped from 25 to $250{ }^{\circ} \mathrm{C}$ at a heating rate of $5^{\circ} \mathrm{C} / \mathrm{min}$.

Attenuated Total Reflection Fourier-Transform Infrared Spectroscopy (ATR FTIR). Infrared spectra (Figures S11 and S12) were acquired using a Spectrum One (PerkinElmer) FTIR spectrometer in transmission mode with the attenuated total reflection (ATR) technique from 650 to $4000 \mathrm{~cm}^{-1}$ at a resolution of $2 \mathrm{~cm}^{-1}$. Small pieces of cured resins were crushed manually and used for the measurement, while the diglycidyl esters were used as received after synthesis.

\section{RESULTS AND DISCUSSION}

Diglycidyl Ester Synthesis. As the initial starting point of the study, furan-based diglycidyl esters $\mathbf{1}$ and $\mathbf{2}$ were prepared from FDCA and BFDCA, respectively. While the synthesis of the furan ester (1) has been reported, the synthesis of the bifuran ester (2) has not been reported so far to the best of our knowledge. Monomer $\mathbf{1}$ has been previously synthesized through the oxidation of the corresponding allyl ester with meta-chloroperoxybenzoic acid. ${ }^{15,16}$ The allyl ester in turn was prepared from FDCA and allyl bromide. This route is reported to give diglycidyl ester 1 in ca. $60 \%$ yield over two steps. However, we found the lower solubility of BFDCA and its simple esters problematic during the oxidation of the allyl ester derivative, as unimpressive crude yields were afforded even with an excess of reagents and long reaction times. Instead, we turned to a simple esterification of BFDCA with glycidol through a diacyl chloride intermediate. An isolated overall yield of $87 \%$ was achieved for diglycidyl ester 2 starting from BFDCA, and diglycidyl ester 1 was furnished in an $89 \%$ yield starting from FDCA. While the more straightforward and industrially relevant route using epichlorohydrin is fathomable, oligomeric products could form more easily and would take additional steps to remove. However, it is important to note that due to the useful properties of similar simple diglycidyl esters, promising new "green" syntheses related to these types of compounds have also been reported quite recently. ${ }^{37,38}$

According to ${ }^{1} \mathrm{H}$ NMR analysis (Figure 1), the desired monomeric diglycidyl esters were prepared in good purity through the diacyl chloride intermediate. The melting points obtained via DSC also pointed to the successful synthesis and isolation: the previously reported melting point $\left(T_{\mathrm{m}}=88\right.$ $\left.{ }^{\circ} \mathrm{C}^{37}\right)$ for diglycidyl ester 1 was closely matched here $\left(T_{\mathrm{m}}=89\right.$ ${ }^{\circ} \mathrm{C}$ ), while bifuran diglycidyl ester 2 was found to have a significantly higher melting point $\left(T_{\mathrm{m}}=165{ }^{\circ} \mathrm{C}\right)$. The high melting point and relatively low solubility (in, e.g., acetone, ethyl acetate, and dichloromethane) of $\mathbf{2}$ can be somewhat problematic in some applications as handling and formulation of epoxy resins using diglycidyl ester $\mathbf{2}$ would become challenging. However, its planarity and high melting point do suggest possible usefulness in high- $T_{\mathrm{g}}$ epoxy resins if the physical characteristics could be overcome. Here, it was discovered that the derivatization into dimethacrylates can be used to obtain liquid monomers reminiscent of BisGMA, which should broaden the potential applications.

Synthesis of Dimethacrylates and Their Properties. Reacting diglycidyl esters $\mathbf{1}$ and $\mathbf{2}$ with 3 equiv of methacrylic acid (MAA) and 1 equiv of triethylamine readily gave the 
respective dimethacrylates $\mathrm{FD}$ and $\mathrm{BfD}$ in good yields, and complete conversion could be observed after an overnight reaction at $70{ }^{\circ} \mathrm{C}$. Careful ${ }^{1} \mathrm{H}$ NMR analysis revealed that the addition of methacrylic acid gave rise to different end groups (Figure 2). The presence of two different end groups was expected on the basis that the attack of the nucleophile can occur at either of the carbons of the oxirane ring, giving end groups $\mathbf{A}$ and $\mathbf{B}{ }^{39}$ As further analysis shows, the attack of methacrylic acid at the more hindered carbon (resulting in end group B) is made apparent by the quintet at ca. $5.3 \mathrm{ppm}$ in the ${ }^{1} \mathrm{H}$ NMR spectra. However, an additional quintet at ca. 5.4 ppm can be observed as well. Two-dimensional (2D) NMR (HMBC) indicated that the quintet proton at $5.4 \mathrm{ppm}$ was coupled over three bonds to the furan $\mathrm{C}=\mathrm{O}$ carbon, while the proton at $5.3 \mathrm{ppm}$ was coupled over three bonds to the methacrylic $\mathrm{C}=\mathrm{O}$ carbon. Further $2 \mathrm{D}$ NMR analysis allowed the structure of the end groups to be elaborated (Figures S13$\mathrm{S} 21)$. In certain aspects, this end group isomerism is very similar to that observed in BisGMA ${ }^{40}$ and shares similar characteristics with dimethacrylates obtained via the oxirane ring opening with carboxylic acids. ${ }^{41}$

The unusual structure of end group $\mathbf{C}$ cannot form directly by the expected ring opening. It is likely that an intramolecular transesterification is involved, perhaps occurring due to the presence of a base. Because a significant portion of isomeric end groups $\mathbf{B}$ and $\mathbf{C}$ were formed as well, dimethacrylates FD and $\mathrm{BfD}$ are expected to consist of up to six different structural isomers, which would be quite unfeasible to separate. Since conversion into dimethacrylates was complete, and the ${ }^{1} \mathrm{H}$ NMR integrals show that both furan-based dimethacrylates had ${ }^{1} \mathrm{H}$ integrals in the expected ratio (e.g., the area ratio of peaks $\mathrm{a}^{\prime \prime}$ and $\mathrm{b}$ in Figure $2 \mathrm{~b}$ is $\left.\sim 1: 1\right)$, they were used as synthesized.

In the interest of modifying the end group ratios, we also tried a base-free approach to the addition reaction. Specifically, 1,1,1,3,3,3-hexafluoroisopropanol (HFIP), a fluorinated alcohol that can reportedly activate epoxies, ${ }^{42}$ was used as the solvent to see whether the product mixture might be simplified in the absence of a base. The reaction was first attempted with diglycidyl ester 2, which also turned out to be highly soluble in HFIP at room temperature. After $50 \mathrm{~h}$ at $65{ }^{\circ} \mathrm{C}$, diglycidyl ester 2 disappeared completely according to TLC analysis, and NMR analysis confirmed the addition of methacrylic acid. Surprisingly, furan diglycidyl ester $\mathbf{1}$ had a lower conversion and the purity of the resultant dimethacrylate was low despite the long reaction time (ca. $90 \%$ conversion after $50 \mathrm{~h}$ at 65 $\left.{ }^{\circ} \mathrm{C}\right)$. However, ${ }^{1} \mathrm{H}$ NMR analysis revealed that HFIP not only mediated the addition of methacrylic acid but, in both cases, also appeared to prompt an accompanying rearrangement of the end group: HFIP mainly catalyzed the formation of end group $\mathbf{C}$ (Figure 3). Comparison of the end group ratios reveals that, with diglycidyl ester $\mathbf{2}$ as the substrate, the ratio of end groups $\mathbf{A}$ and $\mathbf{C}$ becomes essentially inverted when compared to that of the base-catalyzed reaction. Since complete conversion into a dimethacrylate in HFIP was easily accomplished from diglycidyl ester 2 , the resulting product designated as "i-BfD" was also characterized in further experiments.

While elucidating the mechanism behind this surprising result is not the focus of this work, in the following, we will attempt to provide some rationalization for the result: two control experiments were done to show the important role of HFIP in the reaction. First, the reaction was attempted by substituting HFIP with 2-propanol, which predictably failed to convert diglycidyl ester $\mathbf{2}$ into the desired dimethacrylate. Second, the possibility that HFIP could induce an intramolecular transesterification after the methacrylate moiety was formed could be excluded on the basis that $\mathrm{BfD}$ was not converted into i-BfD after stirring in HFIP with 1 equiv of methacrylic acid (viz. to mimic the endpoint of the HFIPmediated reaction). These two results would suggest that the addition reaction of methacrylic acid in HFIP takes place through a pathway that includes a simultaneous rearrangement of the end group. While speculating, this end group may form preferentially due to the intramolecular activation facilitated by HFIP (Scheme 3i), as intramolecular activation of glycidyl esters has been implicated as a possible pathway for the ring opening in the past (Scheme 3ii). ${ }^{43,44}$

Scheme 3. Proposed Mechanism for the Activation of Glycidyl Esters in HFIP and the Following Formation of End Group C

i) A proposed pathway for furan glycidyl ester activation in HFIP:

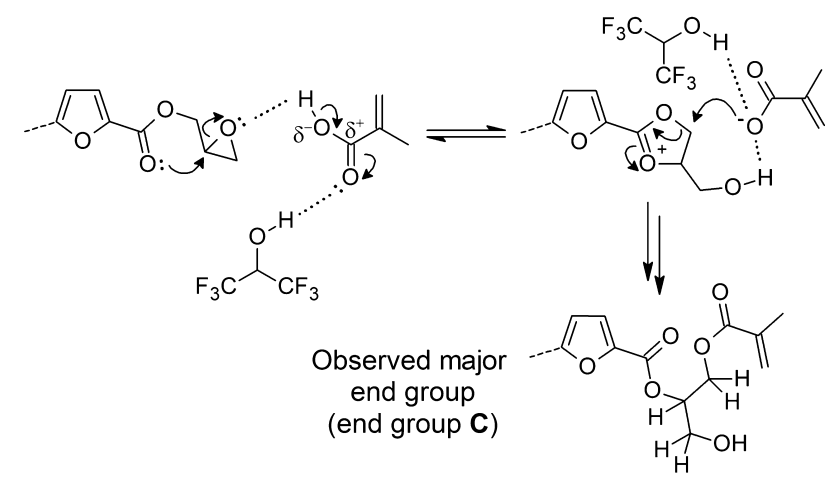

ii) Previously suggested mechanism for the oxirane ring opening of glycidyl esters with trifluoroacetic anhydride ${ }^{43}$ :

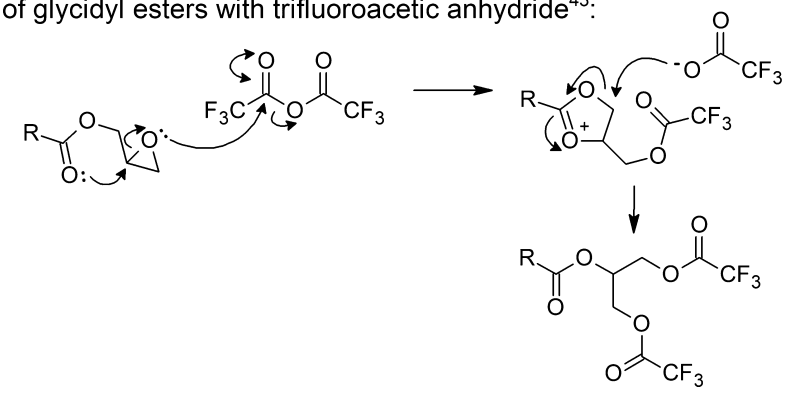

While the exact interactions of HFIP can only be speculated, such a pathway would offer a reason for the different reactivity and end group ratio observed between diglycidyl esters $\mathbf{1}$ and 2 , since the carbonyl group of the furan ring would have to assist in the activation of the oxirane ring. A positive charge should accumulate in the vicinity of this carbon atom, and it is not unreasonable that bifuran diglycidyl ester 2 would be able to delocalize the charge more effectively over the larger, more conjugated heteroaromatic system. Thus, a tentative explanation would be provided for the higher degree of end group $\mathbf{C}$ formed when diglycidyl ester $\mathbf{2}$ was used as the substrate. However, direct addition to the oxirane ring also appears to be taking place, as end groups $\mathbf{A}$ and $\mathbf{B}$ were formed in small amounts.

For a real-world application, the viscosity of a methacrylate monomer may be important since it can influence handling 

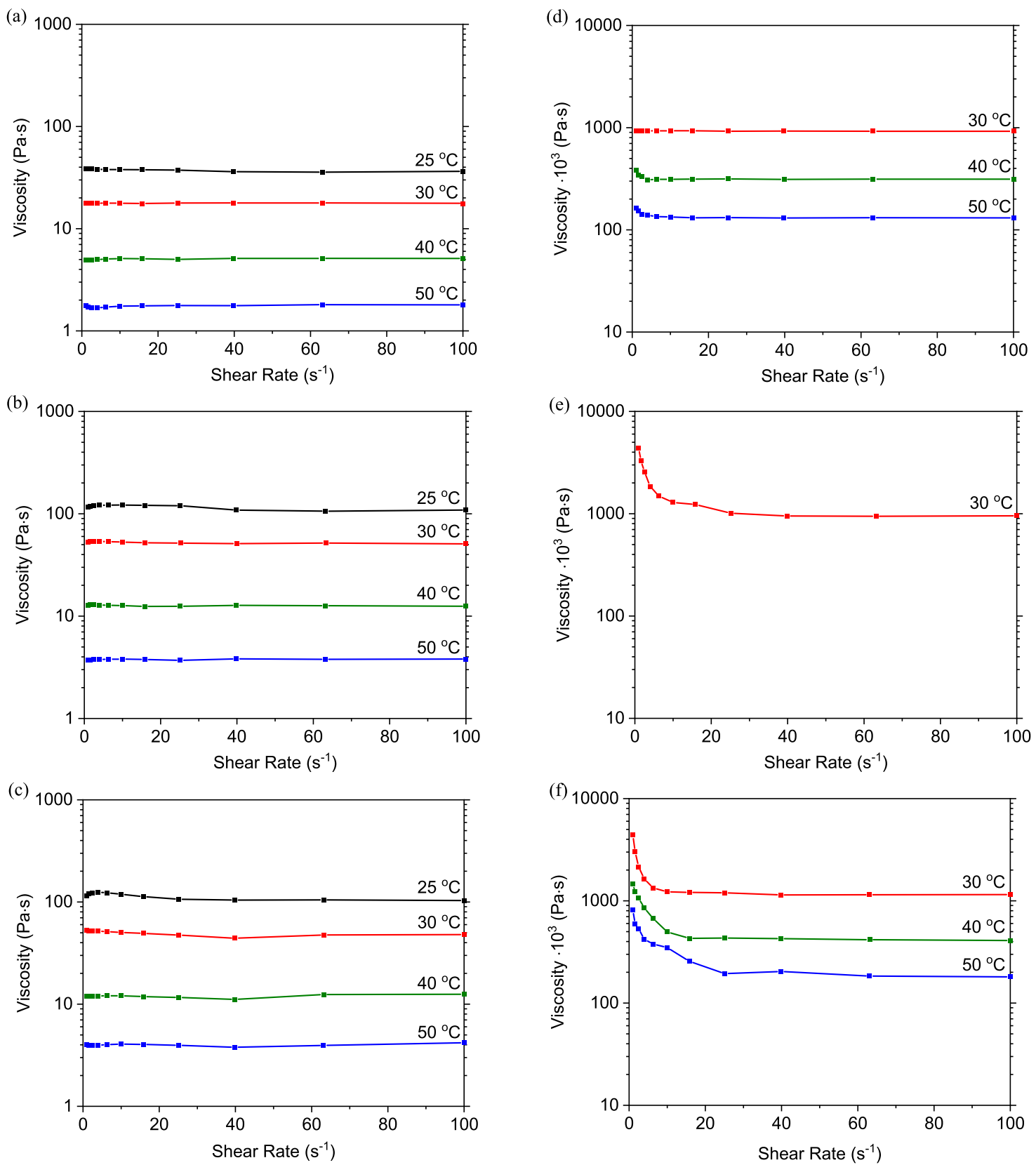

Figure 4. Dynamic viscosities measured at different temperatures for neat $\mathrm{FD}(\mathrm{a})$, neat $\mathrm{BfD}(\mathrm{b})$, neat i-BfD (c), $\mathrm{FD}_{60} \mathrm{ME}_{40}(\mathrm{~d}), \mathrm{BfD}_{60} \mathrm{ME}_{40}(\mathrm{e}), \mathrm{and}$ $\mathrm{i}-\mathrm{BfD}_{60} \mathrm{ME}_{40}$ (f).

and formulation. Due to the presence of the free hydroxyl groups, the prepared dimethacrylates show high viscosities (Figure $4 a-c)$. However, the values are notably lower than those commonly reported for BisGMA (e.g., $1200 \mathrm{~Pa} \cdot \mathrm{s}$ at 20 ${ }^{\circ} \mathrm{C}^{41}$ and $593 \mathrm{~Pa} \cdot \mathrm{s}$ at $25{ }^{\circ} \mathrm{C}^{45}$ ). On the other hand, the corresponding dimethacrylates prepared from isophthalic and phthalic acids have been reported to have viscosities of only 8 $\mathrm{Pa} \cdot \mathrm{s}$ or less at $20^{\circ} \mathrm{C}$, whereas a solid dimethacrylate $\left(T_{\mathrm{m}}=103\right.$ ${ }^{\circ} \mathrm{C}$ ) was obtained from terephthalic acid. ${ }^{41}$ There, the results were explained by the highly favorable intramolecular hydrogen bonding or its absence in the case of the terephthalic acid derivative. Comparing the average viscosities of $\mathrm{BfD}$, i-BfD, and $\mathrm{FD}$ at $25^{\circ} \mathrm{C}(116,114$, and $38 \mathrm{~Pa} \cdot \mathrm{s}$, respectively), a large difference can be observed between the furan and bifuran dimethacrylates. This might in part be due to the rigidity and planarity of the bifuran units, which are subsequently expected to have stronger intermolecular interactions. To lower their viscosities, and to more reasonably assess their potential in fulfilling a BisGMA-like role, the three furan dimethacrylates were combined with methacrylated eugenol (ME). Dilution with 40 wt \% of ME lowered the viscosities roughly by an order of magnitude (Figure 4d-f). Both bifuran-based formulations also showed prominent shear thinning at each temperature, though their viscosities at higher shear rates settled to values quite comparable with $\mathrm{FD}_{60} \mathrm{ME}_{40}$. Still, a slight elevation of temperature was required for the mixtures to approach a more desirable viscosity in the range of $1 \mathrm{~Pa} \cdot \mathrm{s}$ or less.

The $\mathrm{BfD}_{60} \mathrm{ME}_{40}$ formulation was noted to be prone to a slow crystallization and separation of the bifuran dimethacrylate: if left standing for 2-3 days at room temperature, small crystalline precipitates could be observed within the viscous 
liquid. The viscosity value was also only obtained at $30{ }^{\circ} \mathrm{C}$, as the mixture became a thick slurry once the measurement was continued past $30{ }^{\circ} \mathrm{C}$, giving anomalous results. The resin could, however, be dissolved in, e.g., dichloromethane and dried to yield a homogeneous liquid once again, though heating the partially solidified mixture to $70-80{ }^{\circ} \mathrm{C}$ was not able to homogenize it. In contrast, $\mathrm{i}-\mathrm{BfD}_{60} \mathrm{ME}_{40}$ or neat $\mathrm{i}-\mathrm{BfD}$ was not observed to behave in this way. We conclude that components with relatively high melting points are present in $\mathrm{BfD}$, but their crystallization is probably hindered by the presence of the various structural isomers. In this respect, i-BfD with its modified ratio of the end groups $\mathbf{A}$ and $\mathbf{C}$ can be considered to have an advantage.

Curing and Cured Properties of the Methacrylate Resins. Next, the curing of neat and mixed resins was characterized using DSC (Figure S22) with tert-butyl peroxybenzoate as the initiator. The reaction enthalpy of the curing was found to be correlated with the molar mass of the methacrylate (Table 1). Accordingly, ME presented the

Table 1. Curing Behavior of Resins (DSC), and TGA of $8 \mathrm{~h}$ Cured Resin Systems ${ }^{a}$

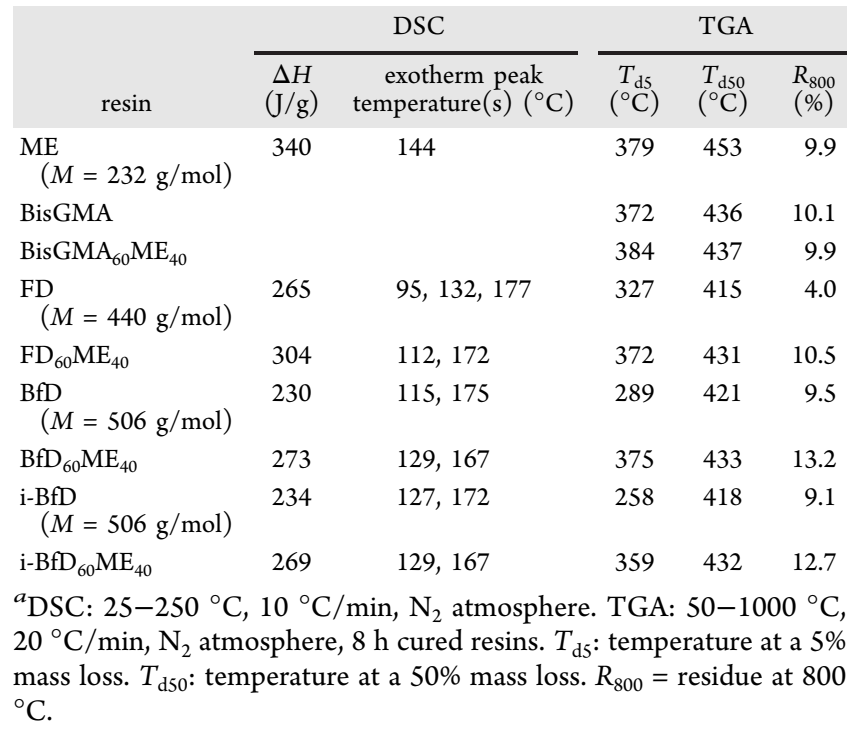

highest enthalpy $(340 \mathrm{~J} / \mathrm{g})$, while neat bifuran dimethacrylates $\mathrm{BfD}$ and $\mathrm{i}-\mathrm{BfD}$ had the lowest reaction enthalpies. Also, the peak of the exothermic cure was noticeably shifted between the different methacrylates (Figure S22a): due to the low onset temperature of $\mathrm{FD}$, it was handled at room temperature once mixed with the peroxide to prevent gelling prior to the measurement, whereas the others could be vacuum-dried faster at slightly elevated temperatures after homogenizing in dichloromethane. An important conclusion that may be drawn from the DSC data is the fact that the bifuran-based resins had practically matching reaction enthalpies, which indicated identical methacrylate content. The diluted compositions had very similarly shaped DSC traces (Figure S22b) as well, whereas the undiluted $\mathrm{i}-\mathrm{BfD}$ had a slightly delayed cure compared to neat BfD (Figure S22a).

For TGA and DMA, solid resin specimens were obtained by mixing the initiator with the monomers, which were transferred into molds followed by an $8 \mathrm{~h}$ thermal curing cycle under an inert atmosphere. In DSC analyses after curing, the diluted resins displayed only minor exothermic events due to postcuring at ca. $180{ }^{\circ} \mathrm{C}$, which corresponded to the shoulders or peaks also observed in Figure S22. The observed enthalpies were less than $5 \%$ of the $\Delta H$ values listed in Table 1 ; i.e., only small amounts of the available reactive double bonds were left intact in the $8 \mathrm{~h}$ cure, assuming that the DSC runs achieved the highest conversion possible in each case. The less reactive allylic double bond of methacrylated eugenol probably contributed to this phenomenon, as the neat dimethacrylates displayed no exothermic events in DSC after curing. Supporting the lower reactivity of allylic double bonds in the curing, Soxhlet extracts obtained from the diluted resins and ME clearly contained compounds with the allylic group (Figure S24). However, the diluted resins showed a negligible mass loss, whereas neat ME lost ca. $5 \%$ of its mass (Table S1).

Thermogravimetric analysis indicated that the introduction of the furan ester moieties results in decreased thermal stabilities (Table 1 and Figure S23). Relative to BisGMA controls, an earlier onset on decomposition was observed in each case. This was particularly noticeable for $\mathrm{i}-\mathrm{BfD}$, and to a lesser extent $\mathrm{i}-\mathrm{BfD}_{60} \mathrm{ME}_{40}$, and may be linked to the higher number of primary alcohol groups in the said resins. Still, the $T_{\mathrm{d} 50}$ values were high throughout $\left(>400{ }^{\circ} \mathrm{C}\right)$, suggesting good thermal stability, especially when $\mathrm{ME}$ was used as a reactive diluent as it seemed to have a suppressing effect on the onset of decomposition. Char-yields were similar in all cases except for neat FD, which gave the least residue (Table $1, R_{800}$ ).

Finally, the cured resin specimens were subjected to DMA in tensile mode (Figure 5 and Table 2). $\mathrm{FD}_{60} \mathrm{ME}_{40}, \mathrm{BfD}_{60} \mathrm{ME}_{40}$, and $\mathrm{i}-\mathrm{BfD}_{60} \mathrm{ME}_{40}$ were observed to behave quite similarly relative to the BisGMA-based control: BisGMA ${ }_{60} \mathrm{ME}_{40}$ had a slightly higher storage modulus and showed noticeably lower $\tan \delta$ values, but ultimately had very similar $T_{\mathrm{g}}$. With the neat resins, different trends were observed. First, $\mathrm{ME}$ had the lowest $T_{\mathrm{g}}$ at $149{ }^{\circ} \mathrm{C}$, which is similar to the previous characterization of cross-linked $\mathrm{ME}\left(\tan \delta\right.$ peak at $\left.139^{\circ} \mathrm{C}^{45}\right)$. The material has a high storage modulus but is brittle, and the material was found to be easily chipped or cracked. All of the dimethacrylates were less brittle by comparison and showed elevated glass-transition temperatures. The undiluted furan resins all cured into thermosets with the same $T_{\mathrm{g}}$ at ca. $180^{\circ} \mathrm{C}$, whereas the neat BisGMA resulted in a $T_{\mathrm{g}}$ of ca. $200{ }^{\circ} \mathrm{C}$, the same as its diluted counterpart BisGMA ${ }_{60} \mathrm{ME}_{40}$.

There were some differences in the thermomechanical response between $\mathrm{i}-\mathrm{BfD}_{60} \mathrm{ME}_{40} / \mathrm{i}-\mathrm{BfD}$ and $\mathrm{BfD}_{60} \mathrm{ME}_{40} / \mathrm{BfD}$ that were visible, even though no appreciable differences in the postcuring were found in DSC. Most notably, the peak on $\tan \delta$ was shifted to a higher temperature and appeared more prominent for $\mathrm{i}-\mathrm{BfD}_{60} \mathrm{ME}_{40}$ when compared to that for $\mathrm{BfD}_{60} \mathrm{ME}_{40}$. The broad but weak relaxation appearing at a low temperature (ca. $85{ }^{\circ} \mathrm{C}$ ) was also more prominent. Without the diluent, the glass-transition temperatures appear closer together with sharper $\tan \delta$ peaks, and there seems to be little difference between $\mathrm{BfD}$ and $\mathrm{i}-\mathrm{BfD}$. These results indicate that the end group configuration may modify the behavior of dimethacrylates and may confer differing thermomechanical properties.

Of the tested resin systems, $\mathrm{i}-\mathrm{BfD}_{60} \mathrm{ME}_{40}$ and $\mathrm{FD}_{60} \mathrm{ME}_{40}$ compared most favorably to the BisGMA control. When cured to a high degree, they attained glass-transition temperatures of ca. $200{ }^{\circ} \mathrm{C}$, matching that of BisGMA ${ }_{60} \mathrm{ME}_{40}$. The flat $E^{\prime}$ curve of $\mathrm{FD}_{60} \mathrm{ME}_{40}$ in particular suggests a dense cross-linked network due to a higher density of reactive double bonds in the FD monomer relative to the others. The undiluted resins 

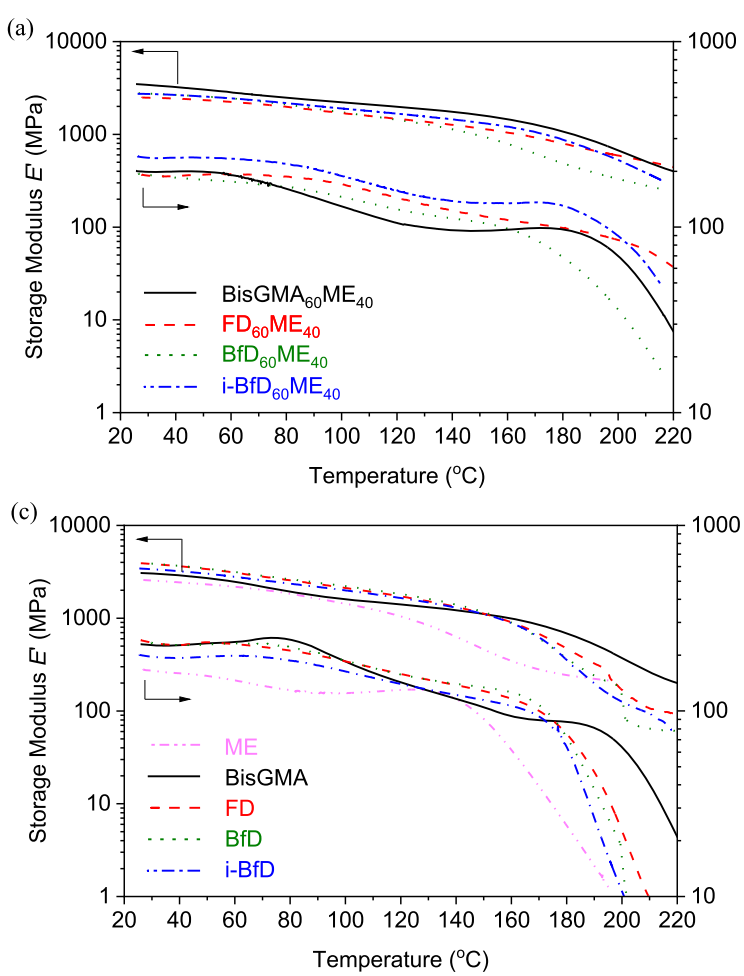
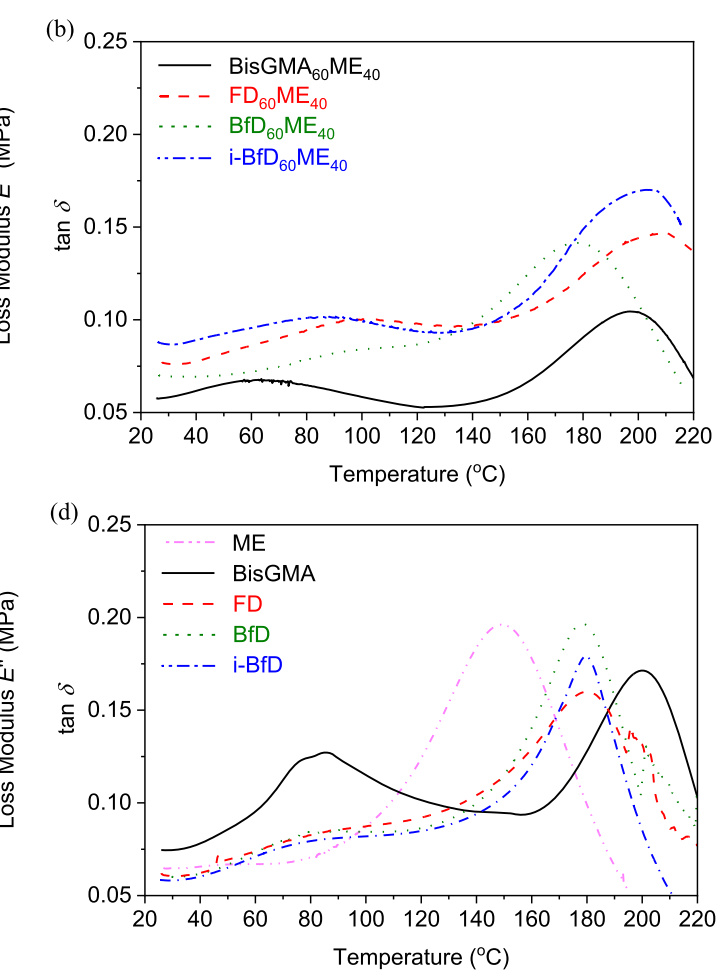

Figure 5. Dynamic mechanical analysis of the diluted (a and b) and neat (c and d) resins after $8 \mathrm{~h}$ cure.

Table 2. Mechanical Properties of Cured Resins Obtained via DMA $^{a}$

\begin{tabular}{lcc}
\multicolumn{1}{c}{ resin } & storage modulus $E^{\prime}(\mathrm{GPa})$ at $25^{\circ} \mathrm{C}$ & $T_{\mathrm{g}}\left({ }^{\circ} \mathrm{C}\right)$ \\
\hline $\mathrm{ME}$ & 2.58 & 149 \\
BisGMA & 3.07 & 199 \\
$\mathrm{FD}$ & 3.91 & 179 \\
$\mathrm{BfD}$ & 3.88 & 178 \\
$\mathrm{i}-\mathrm{BfD}$ & 3.43 & 179 \\
$\mathrm{Bis} \mathrm{GMA}_{60} \mathrm{ME}_{40}$ & 3.48 & 197 \\
$\mathrm{FD}_{60} \mathrm{ME}_{40}$ & 2.49 & 209 \\
$\mathrm{BfD}_{60} \mathrm{ME}_{40}$ & 2.79 & 177 \\
$\mathrm{i}-\mathrm{BfD}_{60} \mathrm{ME}_{40}$ & 2.73 & 203 \\
${ }^{a} T_{\mathrm{g}}:$ temperature at the peak value of tan $\delta$. & \\
\hline
\end{tabular}

showed lower $T_{\mathrm{g}}$ values compared to BisGMA, but the measured storage moduli suggest higher stiffnesses near room temperature. This supports the idea that furan-based dicarboxylic acids could be used as substitutes for the BPA core in certain thermosets without much penalty on the thermomechanical properties.

\section{CONCLUSIONS}

Three furan dimethacrylates were synthesized from the corresponding diglycidyl esters and evaluated as components for thermosetting resins. Due to the furan-based core structures, the prepared monomers incorporated a significant amount of carbon from biomass. Structural isomerism of the methacrylate end groups was characterized, and it was found that an HFIP-mediated ring-opening reaction of a corresponding glycidyl ester could be used to obtain a different ratio of isomers compared to the base-catalyzed reaction with methacrylic acid. For the bifuran-type dimethacrylate, the ratio of isomers was found important for obtaining a liquid resin. The liquid state of all of the dimethacrylates was highly viscous at room temperature, though less viscous than BisGMA. Dilution with methacrylated eugenol could be used successfully to both lower the viscosity and increase the biobased content.

According to the DSC experiments, the furan dimethacrylates were highly reactive toward radical cross-linking. Test specimens cured using an organic peroxide confirmed that furan-based dicarboxylic acids can be a good platform for high $T_{\mathrm{g}}$ dimethacrylates. Glass-transition temperatures in the range of $200{ }^{\circ} \mathrm{C}$ were observed after curing for the resins comprising 60 wt $\%$ furan dimethacrylate and 40 wt \% methacrylated eugenol. A trend of slightly lower glass-transition temperatures and noticeably lower thermal stabilities was observed for the undiluted dimethacrylates. Complete thermal decompositions were observed as single steps at ca. $410-430{ }^{\circ} \mathrm{C}$, whereas for neat methacrylated eugenol, a similar decomposition occurred at $453{ }^{\circ} \mathrm{C}$.

Considering the viscosities and thermomechanical properties compared to similar resins based on bisphenol A, the characterized dimethacrylates showed a clear potential as bio-based alternatives to the BPA-derived resins. The results here also suggest that structural isomerism of the methacrylic end group derived from a glycidyl compound after a ringopening reaction could influence the properties of the uncured and cured resins alike. Based on these initial results, further studies will be conducted in due time related to the HFIPmediated addition and its possible applications related to the reaction between glycidyl methacrylate and dicarboxylic acids.

\section{ASSOCIATED CONTENT}

\section{St Supporting Information}

The Supporting Information is available free of charge at https://pubs.acs.org/doi/10.1021/acsapm.0c00367.

${ }^{1} \mathrm{H}$ NMR spectra of synthesized compounds; ${ }^{13} \mathrm{C}$ NMR and ATR FTIR spectra of diglycidyl esters 1 and 2; ATR 
FTIR spectra of cured resins; ${ }^{13} \mathrm{C}$ NMR spectra of $\mathrm{BfDA} ;{ }^{13} \mathrm{C}$ and $2 \mathrm{D}$ NMR spectra of $\mathrm{FD}, \mathrm{BfD}$, and $\mathrm{i}-\mathrm{BfD}$; DSC traces for curing; TGA traces for cured resins; Soxhlet extraction results; ${ }^{1} \mathrm{H}$ NMR analysis of Soxhlet extracts from cured resins; and ${ }^{1} \mathrm{H}$ NMR spectrum of commercial BisGMA (PDF)

\section{AUTHOR INFORMATION}

\section{Corresponding Author}

Juha P. Heiskanen - Research Unit of Sustainable Chemistry, University of Oulu, FI-90014 Oulu, Finland; 이이. org/ 0000-0002-1884-1583; Email: juha.heiskanen@oulu.fi

\section{Authors}

Tuomo P. Kainulainen - Research Unit of Sustainable Chemistry, University of Oulu, FI-90014 Oulu, Finland; (1) orcid.org/0000-0001-7027-8209

Pyry Erkkilä - Research Unit of Sustainable Chemistry, University of Oulu, FI-90014 Oulu, Finland

Terttu I. Hukka - Chemistry and Advanced Materials, Faculty of Engineering and Natural Sciences, Tampere University, FI33014 Tampere, Finland; ㅇ orcid.org/0000-0001-69269743

Juho A. Sirviö - Fibre and Particle Engineering Research Unit, University of Oulu, FI-90014 Oulu, Finland; orcid.org/ 0000-0002-7404-3340

Complete contact information is available at: https://pubs.acs.org/10.1021/acsapm.0c00367

\section{Author Contributions}

The manuscript was written through the contributions of all authors. All authors have given approval to the final version of the manuscript.

\section{Notes}

The authors declare no competing financial interest.

\section{ACKNOWLEDGMENTS}

The authors declare no competing financial interest. Alfred Kordelin Foundation and Magnus Ehrnrooth Foundation are acknowledged for funding.

\section{REFERENCES}

(1) Dodiuk, H.; Goodman, S. H. Handbook of Thermoset Plastics, 3rd ed.; William Andrew Publishing, 2014.

(2) Brydson, J. A. Plastic Materials, 7th ed.; Butterworth-Heinemann, 1999.

(3) Zeitsch, K. J. The Chemistry and Technology of Furfural and Its Many by-Products, 1st ed.; Elsevier, 2000.

(4) Zhang, J.; Li, J.; Tang, Y.; Lin, L.; Long, M. Advances in catalytic production of bio-based polyester monomer 2,5-furandicarboxylic acid derived from lignocellulosic biomass. Carbohydr. Polym. 2015, 130, 420.

(5) Hu, L.; Lin, L.; Wu, Z.; Zhou, S.; Liu, S. Recent advances in catalytic transformation of biomass-derived 5-hydroxymethylfurfural into the innovative fuels and chemicals. Renewable Sustainable Energy Rev. 2017, 74, 230.

(6) Zhang, Z.; Huber, G. W. Catalytic oxidation of carbohydrates into organic acids and furan chemicals. Chem. Soc. Rev. 2018, 47, 1351 .

(7) Kong, X.; Zhu, Y.; Fang, Z.; Kozinski, J. A.; Butler, I. S.; Xu, L.; Song, H.; Wei, X. Catalytic conversion of 5-hydroxymethylfurfural to some value-added derivatives. Green Chem. 2018, 20, 3657.
(8) Wojcieszak, R.; Itabaiana, I. Engineering the future: Perspectives in the 2,5-furandicarboxylic acid synthesis. Catal. Today 2019, 354, 211-217.

(9) Sousa, A. F.; Vilela, C.; Fonseca, A. C.; Matos, M.; Freire, C. S. R.; Gruter, G.-J. M.; Coelho, J. F. J.; Silvestre, A. J. D. Biobased polyesters and other polymers from 2,5-furandicarboxylic acid: a tribute to furan excellency. Polym. Chem. 2015, 6, 5961.

(10) Papageorgiou, G. Z.; Papageorgiou, D. G.; Terzopoulou, Z.; Bikiaris, D. N. Production of bio-based 2,5-furan dicarboxylate polyesters: Recent progress and critical aspects in their synthesis and thermal properties. Eur. Polym. J. 2016, 83, 202.

(11) Gandini, A. The furan/maleimide Diels-Alder reaction: A versatile click-unclick tool in macromolecular synthesis. Prog. Polym. Sci. 2013, 38, 1-29.

(12) Gandini, A.; Carvalho, A. J. F.; Trovatti, E.; Kramer, R. K.; Lacerda, T. M. Macromolecular materials based on the application of the Diels-Alder reaction to natural polymers and plant oils. Eur. J. Lipid Sci. Technol. 2018, 120, No. 1700091.

(13) Ma, S.; Li, T.; Liu, X.; Zhu, J. Research progress on bio-based thermosetting resins. Polym. Int. 2016, 65, 164.

(14) Cho, J. K.; Lee, J.-S.; Jeong, J.; Kim, B.; Kim, B.; Kim, S.; Shin, S.; Kim, H.-J.; Lee, S.-H. Synthesis of carbohydrate biomass-based furanic compounds bearing epoxide end group(s) and evaluation of their feasibility as adhesives. J. Adhes. Sci. Technol. 2013, 27, 2127.

(15) Deng, J.; Liu, X.; Li, C.; Jiang, Y.; Zhu, J. Synthesis and properties of a bio-based epoxy resin from 2,5-furandicarboxylic acid (FDCA). RSC Adv. 2015, 5, 15930.

(16) Meng, J.; Zeng, Y.; Chen, P.; Zhang, J.; Yao, C.; Fang, Z.; Guo, $\mathrm{K}$. New ultrastiff bio-furan epoxy networks with high $\mathrm{T}_{\mathrm{g}}$ : Facile synthesis to excellent properties. Eur. Polym. J. 2019, 121, No. 109292.

(17) Meng, J.; Zeng, Y.; Chen, P.; Zhang, J.; Yao, C.; Fang, Z.; Ouyang, P.; Guo, K. Flame Retardancy and Mechanical Properties of Bio-Based Furan Epoxy Resins with High Crosslink Density. Macromol. Mater. Eng. 2019, No. 1900587.

(18) Hu, F.; La Scala, J. J.; Sadler, J. M.; Palmese, G. R. Synthesis and Characterization of Thermosetting Furan-Based Epoxy Systems. Macromolecules 2014, 47, 3332.

(19) Choura, M.; Belgacem, N. M.; Gandini, A. Acid-Catalyzed Polycondensation of Furfuryl Alcohol: Mechanisms of Chromophore Formation and Cross-Linking. Macromolecules 1996, 29, 3839.

(20) Goiti, E.; Huglin, M. B.; Rego, J. M. Some observations on the copolymerization of styrene with furfuryl methacrylate. Polymer 2001, $42,10187$.

(21) Peutzfeldt, A. Resin composites in dentistry: the monomer systems. Eur. J. Oral Sci. 1997, 105, 97.

(22) Van Landuyt, K. L.; Snauwaert, J.; De Munck, J.; Peumans, M.; Yoshida, Y.; Poitevin, A.; Coutinho, E.; Suzuki, K.; Lambrechts, P.; Van Meerbeek, B. Systematic review of the chemical composition of contemporary dental adhesives. Biomaterials 2007, 28, 3757.

(23) Jeong, J.; Kim, B.; Shin, S.; Kim, B.; Lee, J.-S.; Lee, S.-H.; Cho, J. K. Synthesis and Photo-Polymerization of Bio-Based Furanic Compounds Functionalized by 2-Hydroxypropyl Methacrylate Group(s). J. Appl. Polym. Sci. 2013, 127, 2483.

(24) Sadler, J. M.; Nguyen, A.-P.; Greer, S. M.; Palmese, G. R.; La Scala, J. J. Synthesis and Characterization of a Novel Bio-Based Reactive Diluent as a Styrene Replacement. J. Biobased Mater. Bioenergy 2012, 6, 86.

(25) Zhu, S.; Li, X.; Xiao, G. Bio-Based Resin for Preparation of Toner with High Mechanism Properties and Thermal Properties and Its Preparation Method. Faming Zhuanli Shenqing. CN Patent CN107840923A2018, p 20180327.

(26) Miyagawa, N.; Ogura, T.; Okano, K.; Matsumoto, T.; Nishino, T.; Mori, A. Preparation of Furan Dimer-based Biopolyester Showing High Melting Points. Chem. Lett. 2017, 46, 1535.

(27) Kainulainen, T. P.; Hukka, T. I.; Özeren, H. D.; Sirviö, J. A.; Hedenqvist, M. S.; Heiskanen, J. P. Utilizing Furfural-Based Bifuran Diester as Monomer and Comonomer for High-Performance Bioplastics: Properties of Poly(butylene furanoate), Poly(butylene 
bifuranoate), and Their Copolyesters. Biomacromolecules 2020, 21, 743.

(28) Stanzione, J. F.; Sadler, J. M.; La Scala, J. J.; Wool, R. P. Lignin Model Compounds as Bio-Based Reactive Diluents for Liquid Molding Resins. ChemSusChem 2012, 5, 1291.

(29) Jaswal, S.; Gaur, B. Green methacrylated lignin model compounds as reactive monomers with low VOC emission for thermosetting resins. Green Process. Synth. 2015, 4, 191.

(30) Liu, K.; Madbouly, S. A.; Kessler, M. R. Biorenewable thermosetting copolymer based on soybean oil and eugenol. Eur. Polym. J. 2015, 69, 16.

(31) Zhang, Y.; Li, Y.; Thakur, V. K.; Wang, L.; Gu, J.; Gao, Z.; Fan, B.; Wu, Q.; Kessler, M. R. Bio-based reactive diluents as sustainable replacements for styrene in MAESO resin. RSC Adv. 2018, 8, 13780.

(32) Kainulainen, T. P.; Sirviö, J. A.; Sethi, J.; Hukka, T. I.; Heiskanen, J. P. UV-Blocking Synthetic Biopolymer from BiomassBased Bifuran Diester and Ethylene Glycol. Macromolecules 2018, 51, 1822.

(33) Rojo, L.; Vazquez, B.; Parra, J.; Bravo, A. L.; Deb, S.; Roman, J. S. From natural products to polymeric derivatives of "Eugenol": A new approach for preparation of dental composites and orthopedic bone cements. Biomacromolecules 2006, 7, 2751.

(34) Weber, F.; Brückner, R. Asymmetric Dihydroxylation of Esters and Amides of Methacrylic, Tiglic, and Angelic Acid: No Exception to the Sharpless Mnemonic! Eur. J. Org. Chem. 2015, 11, 2428.

(35) Deng, J.; Yang, B.; Chen, C.; Liang, J. Renewable EugenolBased Polymeric Oil-Absorbent Microspheres: Preparation and Oil Absorption Ability. ACS Sustainable Chem. Eng. 2015, 3, 599.

(36) Zhang, Y.; Li, Y.; Wang, L.; Gao, Z.; Kessler, M. R. Synthesis and Characterization of Methacrylated Eugenol as a Sustainable Reactive Diluent for a Maleinated Acrylated Epoxidized Soybean Oil Resin. ACS Sustainable Chem. Eng. 2017, 5, 8876.

(37) Marotta, A.; Ambrogi, V.; Cerruti, P.; Mija, A. Green approaches in the synthesis of furan-based diepoxy monomers. RSC Adv. 2018, 8, 16330.

(38) Tanaka, S.; Nakashima, T.; Maeda, T.; Ratanasak, M.; Hasegawa, J.; Kon, Y.; Tamura, M.; Sato, K. Quaternary Alkyl Ammonium Salt-Catalyzed Transformation of Glycidol to Glycidyl Esters by Transesterification of Methyl Esters. ACS Catal. 2018, 8, 1097.

(39) Camara, F.; Caillol, S.; Boutevin, B. Free radical polymerization study of glycerin carbonate methacrylate for the synthesis of cyclic carbonate functionalized polymers. Eur. Polym. J. 2014, 61, 134.

(40) Fujisawa, S. Nuclear Magnetic Resonance Spectra of Bis-GMA and Iso-bis-GMA. Dent. Mater. J. 1994, 13, 251.

(41) Davy, K. W. M.; Kalachandra, S.; Pandain, M. S.; Braden, M. Relationship between composite matrix molecular structure and properties. Biomaterials 1998, 19, 2007.

(42) Das, U.; Crousse, B.; Kesavan, V.; Bonnet-Delpon, D.; Bégué, J.-P. Facile Ring Opening of Oxiranes with Aromatic Amines in Fluoro Alcohols. J. Org. Chem. 2000, 65, 6749.

(43) Stamatov, S. D.; Stawinski, J. Regioselective opening of an oxirane system with trifluoroacetic anhydride. A general method for the synthesis of 2-monoacyl- and 1,3-symmetrical triacylglycerols. Tetrahedron 2005, 61, 3659.

(44) Shaw, S. E.; Russo, T.; Solomon, D. H.; Qiao, G. G. An alternative pathway for the hydrolysis of epoxy ester compounds. Polymer 2006, 47, 8247.

(45) Zhang, Y.; Li, Y.; Thakur, V. K.; Gao, Z.; Gu, J.; Kessler, M. R. High-performance thermosets with tailored properties derived from methacrylated eugenol and epoxy-based vinyl ester. Polym. Int. 2018, 67,544 . 